\title{
Standardized definitions and concepts of radicality during minimally invasive thymoma resection
}

\author{
Giulia De laco\#, Debora Brascia\#, Alessandro Geronimo, Doroty Sampietro, Angela Fiorella, Marcella \\ Schiavone, Teodora Panza, Francesca Signore, Giuseppe Marulli \\ Thoracic Surgery Unit, Department of Organ Transplantation and Emergency, University Hospital of Bari, Bari 70124, Italy. \\ \#These two authors equally contributed to the writing of the work.
}

Correspondence to: Prof. Giuseppe Marulli, Thoracic Surgery Unit, Department of Organ Transplantation and Emergency, University Hospital of Bari, Piazza Giulio Cesare 11, Bari 70124, Italy. E-mail: giuseppe.marulli@uniba.it; beppemarulli@libero.it

How to cite this article: De laco G, Brascia D, Geronimo A, Sampietro D, Fiorella A, Schiavone M, Panza T, Signore F, Marulli G. Standardized definitions and concepts of radicality during minimally invasive thymoma resection. Mini-invasive Surg 2020;4:63. http://dx.doi.org/10.20517/2574-1225.2020.37

Received: 16 Apr 2020 First Decision: 15 Jun 2020 Revised: 11 Jul 2020 Accepted: 18 Aug 2020 Published: 17 Sep 2020

Academic Editor: Piergiorgio Solli Copy Editor: Cai-Hong Wang Production Editor: Jing Yu

\begin{abstract}
Radical thymectomy is the gold standard treatment for thymoma; in particular, completeness of surgical resection of a well-encapsulated thymoma and adequate margins are considered the most important prognostic factors. According to the International Thymic Malignancy Interest Group instructions, in fact, the thymus should be resected en bloc with its upper cervical poles and the surrounding mediastinal fat and through a no-touch surgical technique. For years, the open approaches have been considered the gold standard treatment for thymic masses, because of technical advantages and proved good oncological results. When applied to properly chosen patients on the basis of the tumor stage, dimension, and histology, minimally invasive approaches could be as effective as open ones in terms of long-term outcomes. To accomplish a minimally invasive thymoma resection, several minimally invasive techniques (transcervical, subxiphoid, thoracoscopic, and robotic) have been described, each presenting advantages and drawbacks. Moreover, when dealing with early stage neoplasms, many authors have proposed to perform the thymomectomy alone, not involving the rest of the thymic gland, but evidence is still imprecise and vague, and some studies have described a higher rate of local recurrence when using this technique. Finally, many studies suggest that surgeons with expertise in minimally invasive lymphadenectomy for lung cancer may easily endorse the idea of nodal dissection, to be performed at least in advanced thymomas involving neighboring structures, large masses, and thymic carcinomas.
\end{abstract}

Keywords: Thymoma, thymectomy, minimally invasive techniques, radicality

\footnotetext{
(@) ( $)$

(C) The Author(s) 2020. Open Access This article is licensed under a Creative Commons Attribution 4.0 International License (https://creativecommons.org/licenses/by/4.0/), which permits unrestricted use, sharing, adaptation, distribution and reproduction in any medium or format, for any purpose, even commercially, as long as you give appropriate credit to the original author(s) and the source, provide a link to the Creative Commons license, and indicate if changes were made.
}

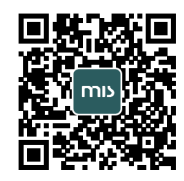




\section{INTRODUCTION}

Thymic neoplasms and malignancies are relatively uncommon. Approximately $90 \%$ of the tumors of the thymus are thymoma, accounting for about $0.2 \%-1.5 \%$ of all cancers. The remaining $10 \%$ are thymic carcinoma, carcinoid tumors, or lymphomas. Indications for thymectomy include suspected thymoma, myasthenia gravis $(\mathrm{MG})$ with and without thymoma, and thymic cists ${ }^{[1-4]}$.

Radical thymectomy is the gold standard treatment for thymoma; in particular, completeness of surgical resection and adequate margins are considered the most important prognostic factors ${ }^{[5,6]}$. Complete surgical resection of a well-encapsulated and noninvasive thymoma is usually curative, with low risks of local recurrence $^{[7]}$. Invasive thymoma and thymic carcinoma could be treated with multimodal therapy including induction or adjuvant chemo- or chemoradiotherapy associated with en-bloc surgical resection. Surgery is also indicated for treatment of local recurrences and, in some cases, pleural and pericardial implants ${ }^{[8]}$. To achieve the most complete surgical resection, the International Thymic Malignancy Interest Group (ITMIG) has suggested two surgical procedures for patients with or without MG [Table 1], respectively: extended thymectomy, including the en bloc removal of the contiguous right and left mediastinal pleura, mediastinal, and pericardiophrenic fatty tissues, and dissection of aorta-pulmonary window, in addition to complete thymectomy [Figure 1] or complete thymectomy, including the en bloc removal of the upper cervical poles and the surrounding mediastinal fat $[\text { Figure } 2]^{[9]}$.

Along with the en bloc resection of thymoma, a no-touch surgical technique should be performed; the thymoma, in fact, should not be grasped or squeezed with retractors because of the possible rupture of the capsule with subsequent pleural dissemination, as Kamel et al. ${ }^{[9]}$ demonstrated. Moreover, areas of potential tissue disruption should be marked immediately during dissection on both the specimen and the patient ${ }^{[10]}$. Completeness of thymectomy should be assessed by macroscopic inspection of the thymic bed, specimen, and subsequent pathological analysis ${ }^{[11]}$. Complete resection (Ro) is defined when there is no evidence of residual tumor (macroscopically and/or microscopically) while incomplete resection is defined when there is evidence of microscopically (R1) or macroscopically $(\mathrm{R} 2)$ residual tumor. When dealing with thymomas, there is often little tissue surrounding the tumor and quite often the capsule itself constitutes the outer surface of the specimen, leading to misleading interpretations of the margins [Figure 3].

In such cases, only through-and-thorough penetration of the capsule by tumor which reaches the outer surface should be interpreted as a positive margin ${ }^{[12]}$. After an Ro resection or a complete radiographic response has been previously achieved and an adequate 5-10 years of follow up has been carried out, recurrence can be defined ${ }^{[10]}$. Given the indolent behavior of many of these tumors, ITMIG has suggested that freedom-from-recurrence (FFR), as calculated from the date of resection to the date of first recurrence, is a better measure than survival in patients who have successfully undergone curative treatment ${ }^{[13]}$. Average recurrence rates are low for Masaoka Stage I tumors (3\%) but increase progressively to $11 \%$ and $30 \%$ for Stage II and III tumors, respectively ${ }^{[14]}$.

For years, the optimal surgical approach, combining the best degree of resection with minor surgical invasiveness, has been discussed ${ }^{[15-18]}$. Minimally invasive approaches have become increasingly relevant in the last two decades and a proved alternative to open techniques, which are still considered the gold standard treatment because of technical advantages and proved good oncological results ${ }^{[19]}$. According to the above-mentioned general principles about radical thymectomies, ITMIG guidelines ${ }^{[10]}$ have been proposed for minimally invasive resections. They should involve no rib spreading or sternal cutting, dissection, and visualization of innominate vein, both phrenic nerves, and pleura in the case of suspected invasion. Moreover, the access incision for retrieval should be large enough to prevent specimen disruption; retrieval should always be done in the bag; and a correct examination of the removed specimen to assess for completeness of the resection is required ${ }^{[10]}$. 


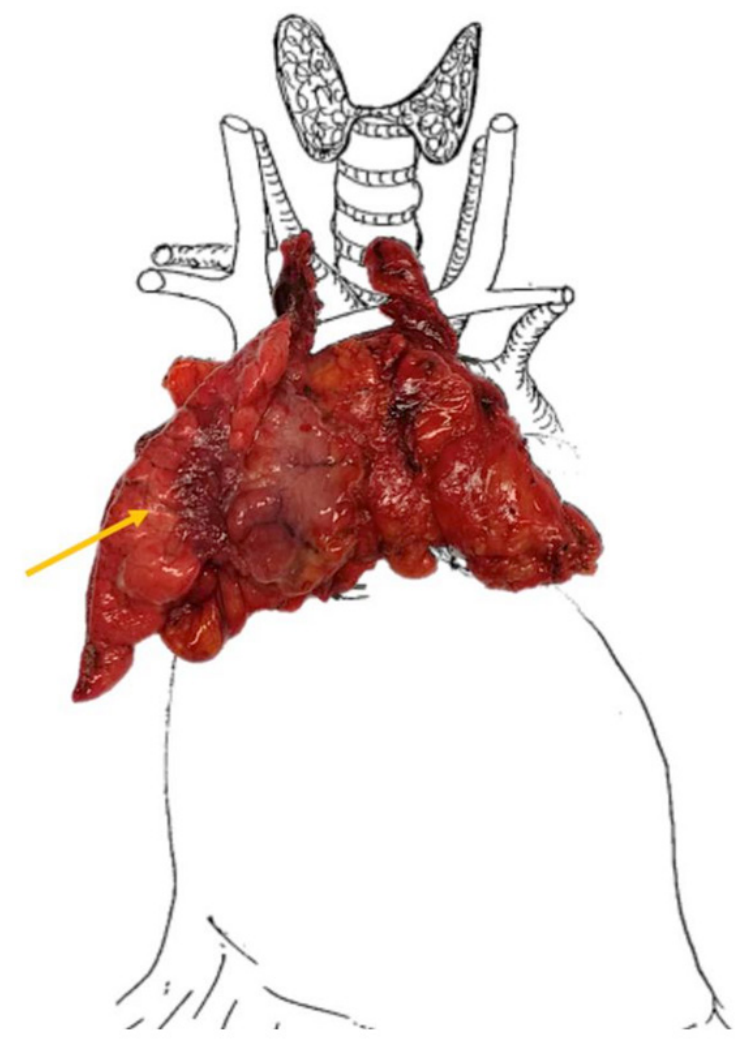

Figure 1. Thymic specimen after en bloc resection for locally advanced thymoma invading the lung (indicated with yellow arrow)
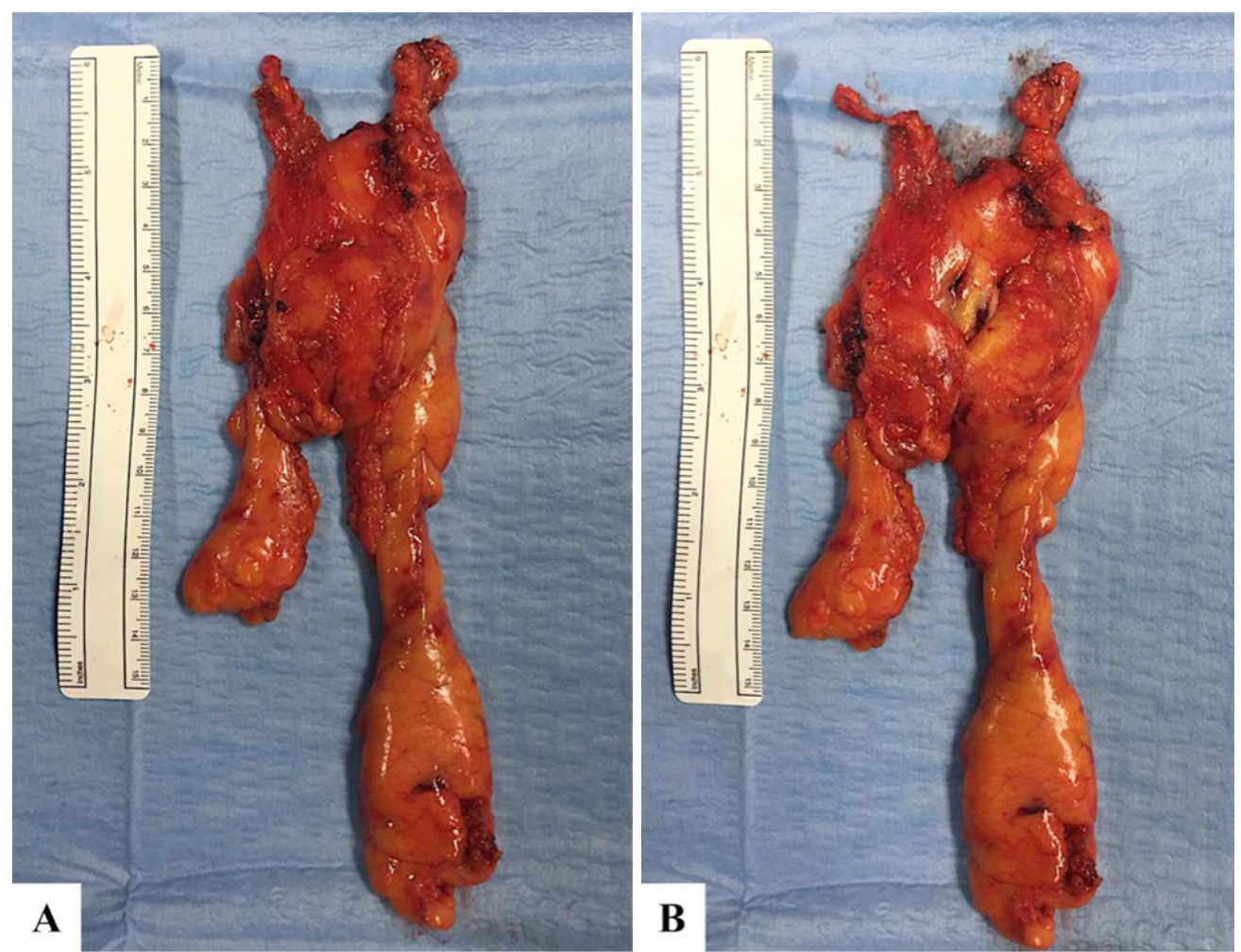

Figure 2. A: Gross specimen after completed video-assisted thoracic surgery thymectomy including all adjacent fat; B: the gross cross section revealed a thymoma $2 \mathrm{~cm}$ in size 


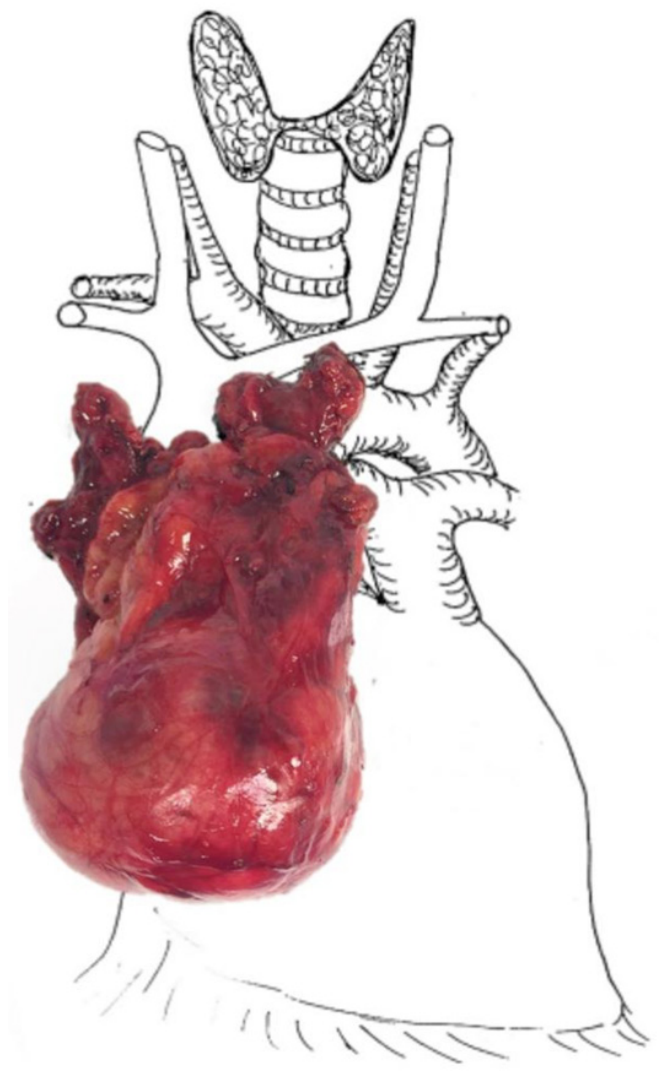

Figure 3. Gross specimen after resection of a well-circumscribed thymoma with a thin fibrous capsule

Table 1. Comparison between extended thymectomy and completed thymectomy

\begin{tabular}{|c|c|c|}
\hline & Extended thymectomy & Completed thymectomy \\
\hline Indication & $\begin{array}{l}\text { Thymic mass } \\
\text { MG } \\
\text { Both }\end{array}$ & $\begin{array}{l}\text { Thymic mass } \\
\text { MG } \\
\text { Both }\end{array}$ \\
\hline Preoperation preparation & $\begin{array}{l}\text { CT/MRI } \\
\text { Neurological evaluation for detection of MG } \\
\text { Plasmapheresis or immunoglobulins in myasthenic } \\
\text { patient }\end{array}$ & $\begin{array}{l}\text { CT/MRI } \\
\text { Neurological evaluation for detection of MG } \\
\text { Plasmapheresis or immunoglobulins in myasthenic } \\
\text { patient }\end{array}$ \\
\hline Resection extent & $\begin{array}{l}\text { Removal of thymus, thymic fat and other mediastinal } \\
\text { structures infiltrated by the mass (pericardium, lung, } \\
\text { etc.) }\end{array}$ & $\begin{array}{l}\text { Removal of the grossly identifiable thymus and } \\
\text { variable amounts of anterior mediastinal fat }\end{array}$ \\
\hline Postoperative care & $\begin{array}{l}\text { Extubation if good respiratory effort and blood gases } \\
\text { Close control of vital signs, especially saturation } \\
\text { Aggressive pulmonary toilet } \\
\text { Early ambulation } \\
\text { Anticholinesterase agents if weakness occurs } \\
\text { Plasmapheresis in case of respiratory standpoint } \\
\text { worsening } \\
\text { Drainage removal in case of patient stability }\end{array}$ & $\begin{array}{l}\text { Extubation if good respiratory effort and blood gases } \\
\text { Close control of vital signs, especially saturation } \\
\text { Aggressive pulmonary toilet } \\
\text { Early ambulation } \\
\text { Anticholinesterase agents if weakness occurs } \\
\text { Plasmapheresis in case of respiratory standpoint } \\
\text { worsening } \\
\text { Drainage removal in case of patient stability }\end{array}$ \\
\hline
\end{tabular}

MG: Myastenia Gravis; MRI: magnetic resonance imaging; CT: computed tomography

The correct indication of the surgical approach in thymic lesions should be chosen on the basis of the tumor stage, dimension, and histology ${ }^{[20]}$. Cheng et al. ${ }^{[21]}$ suggested that patients would be suitable for minimally invasive thymectomy by fulfilling some radiological criteria: location of the tumor in the anterior mediastinum, tumor encapsulation, presence of a distinct fat plane between the tumor and surrounding structures, existence of residual normal appearing thymic tissue, no mass compression effect, and unilateral tumor predominance, particularly for tumors larger than $3 \mathrm{~cm}$ [Figure 4]. 

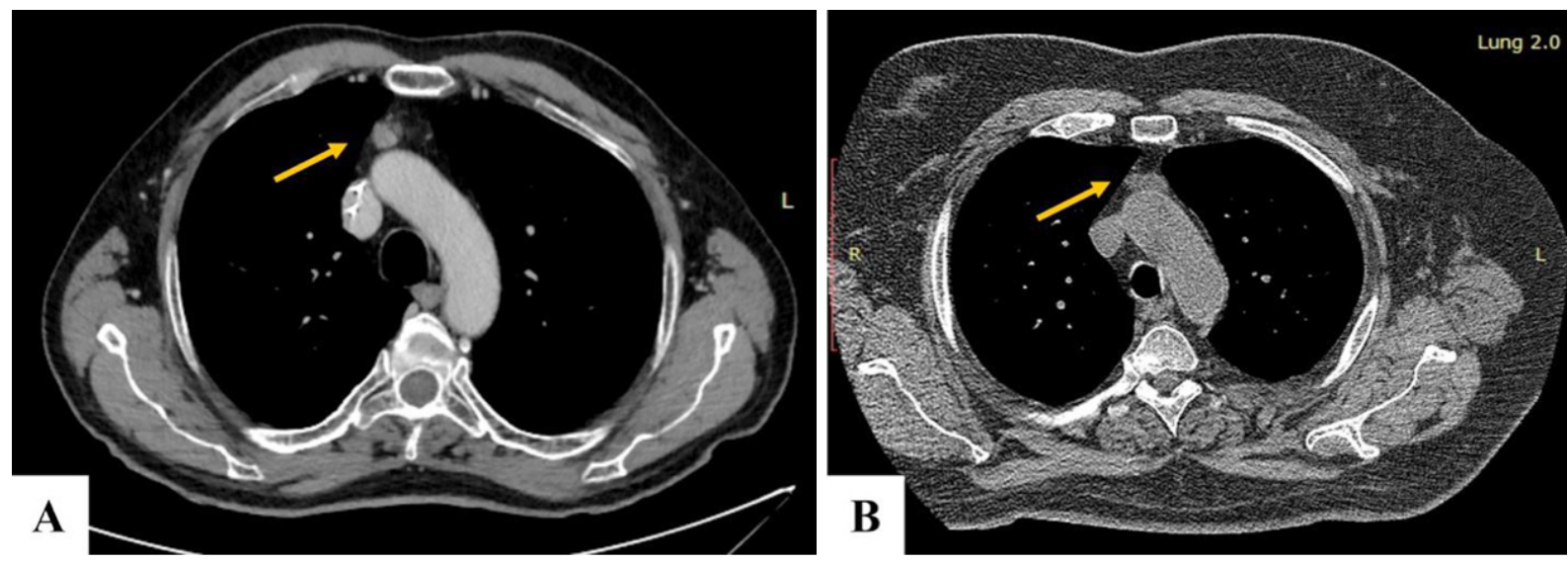

Figure 4. A, B: Computed tomography scan images showing two small thymomas, one (A) with typical calcifications, with regular outlines, amenable to minimally invasive surgery. Histology was positive for type A thymoma (Masaoka-Koga Stage I)

Most published studies agree that thymic lesions larger than $5 \mathrm{~cm}$ should be excluded from the minimally invasive approach; to date, dimension is not considered an absolute contraindication, but big lesions may interfere with the thoracoscopic procedure, forcing a conversion, prolonged operative time, and capsule injuries ${ }^{[22]}$. Kimura et al. ${ }^{[23]}$ reported that tumor capsule injury during video-assisted thoracic surgery (VATS) is observed more frequently in patients with thymomas $>5 \mathrm{~cm}$ and the recent Japanese Alliance for Research in Thymoma (JART) study found statistically more recurrences in patients with thymomas $>5 \mathrm{~cm}^{[24]}$.

Perforation of the capsule, incomplete resection possibility, en bloc resection not achievable, and disruption of the tissues exposing the tumor could compromise the complete oncological resection, and they force conversion to open ${ }^{[10,25]}$.

Several minimally invasive techniques (transcervical, subxiphoid, thoracoscopic, and robotic) have been described to accomplish a minimally invasive thymoma resection, each having advantages and drawbacks.

\section{VIDEO-ASSISTED TRANSCERVICAL THYMECTOMY}

The transcervical approach for thymectomy was first reported by Sauerbruch in $1912^{[26]}$ and then performed by Crile in 1966 in a series of patients with myasthenia gravis ${ }^{[27]}$ and by Kirschner and Kark in the $1970 \mathrm{~s}^{[28,29]}$. It was only in 1988 that Cooper and colleagues ${ }^{[30]}$ reported a modified approach to perform and extend transcervical thymectomy in contrast with the limited technique reported earlier. Extended thymectomy involved use of a sternum-lifting and a self-retaining retractor to improve mediastinal exposure allowing a more complete removal of mediastinal thymic tissue and extrathymic fat. With the spread of new technologies and minimally invasive approaches, in 1993, the thoracoscopic approach for thymectomy was described for the first time ${ }^{[31]}$. The advantages of the video-assisted transcervical thymectomy are those of a transcervical route: lower morbidity and pain, shorter hospitalization, faster patient recovery, and reduced $\operatorname{cost}^{[32]}$; moreover, the uniportal transcervical route obviates entry into the pleural spaces, negates the need for chest tubes, provides enhanced exposure in the neck region, and a splitlung anesthesia via a double-lumen endotracheal tube is not mandatory. It is an efficient and inexpensive procedure with a one-night hospital stay and minimal postoperative pain and discomfort to the patient ${ }^{[33]}$. Relative contraindications to a transcervical approach include prior mediastinal surgery and/or irradiation and cervical spine disorder limiting extension of the neck ${ }^{[33]}$. The main concerns about this technique are about the narrow surgical field leading to instrument crowding and the not complete visualization of the thymus with the subsequent impossibility to perform a complete clearance of the mediastinal fat compared to an open surgery. 
During the years, to surpass these limits, some modified and combined approaches have been described. Ampollini et al ${ }^{[34]}$, for example, described a modified video-assisted transcervical approach, which, using the instruments developed for the minimally invasive thyroidectomy, enable the surgeon to perform the thymectomy without neck hyperextension or permanent sternum elevation, which are mainly responsible for postoperative pain. Yu et al. ${ }^{[35]}$, instead, proposed a combined transcervical and unilateral-thoracoscopic thymectomy approach to reach the residual thymic tissue, which might have been left behind in the superior horns or in the upper poles into the base of the neck.

\section{SUBXIPHOID THYMECTOMY}

The subxiphoid approach was introduced in 1999 by Kido et al. ${ }^{[36]}$, paving the way for Hsu et al. ${ }^{[37]}$, who first performed subxiphoid video-assisted thoracoscopic extended thymectomy in 2002. Since then, the subxiphoid approach has been used successfully and many techniques have been described according to the incision design: the uniportal or dual-port subxiphoid $\operatorname{approach}^{[38-40]}$, the subxiphoid and subcostal arch approach, subxiphoid robotic thymectomy ${ }^{[41,42]}$, and a combination of the transthoracic and subxiphoid approaches ${ }^{[43]}$.

Each technique should be chosen on the basis of the personal preference of the surgeon along with his experience and of the single case to treat, according to its anatomical peculiarities ${ }^{[4]}$. Although the uniportal approach seems to be the most minimally invasive approach in existence, it is not an easy technique to learn because of the reduced instrument maneuverability; however, in skilled hands, this limit could be overcome with specially modified instruments and angled thoracoscopes ${ }^{[45,46]}$. Since the increase in the number of the ports can help obtain a multidirectional view, increasing the safety of the procedure, single-port thymectomy should be started following the training of two- or three-port thymectomy ${ }^{[47]}$. The subxiphoid robotic approach is the one with the best maneuverability: the left and right robot arms are inserted in the 6th intercostal space. and the entire target/thymus lies between the left and right arms, thereby enabling maximum robot performances ${ }^{[42]}$.

The advantages of the subxiphoid approach are numerous; since the camera is inserted into a subxiphoid incision in the midline of the body, the surgical field is comparable to that in a median sternotomy. This helps identify the location of the bilateral phrenic nerves and confirm the location of the superior pole of the thymus while offering a good visualization in the neck area and a safe dissection of thymic veins ${ }^{[42]}$. Other advantages include minimal postoperative pain with no occurrence of intercostal neuropathy since intercostal spaces are not traversed and cosmetic outcomes are excellent ${ }^{[43,44,48]}$. In contrast, when comparing the subxiphoid view to the lateral one in the traditional VATS, it becomes difficult to identify the contralateral phrenic nerve, and there is also the risk of intercostal nerve injury, resulting in postoperative chronic incision pain ${ }^{[43,49]}$. Zhang et al. ${ }^{[43]}$ recently conducted a retrospective analysis comparing 98 patients who underwent a VATS thymectomy through the subxiphoid and subcostal arch approach or the lateral intercostal one. They found statistically significative differences in the length of hospital stay, postoperative pain, and cosmetic satisfaction in favor of the subxiphoid approach.

To deal with larger thymomas and difficult selected cases, some modified approaches have been described. In their experience, Zieliński et al. ${ }^{[16]}$ proposed a "maximal" transcervical subxiphoid video-thoracoscopic thymectomy, in which, at the same time, two teams work from above and below the sternum to dissect the thymus while using a double sternal elevator. This technique has the advantage to be more extensive in regard to the removal of fatty tissue from the aorta-caval groove and fatty tissue anterior to the trachea, almost reaching the level of tracheal bifurcation. On the other hand, even if the two-team approach helps to reduce the operative time, it is a far more invasive technique than unilateral VATS affected by more complications than traditional VATS. 

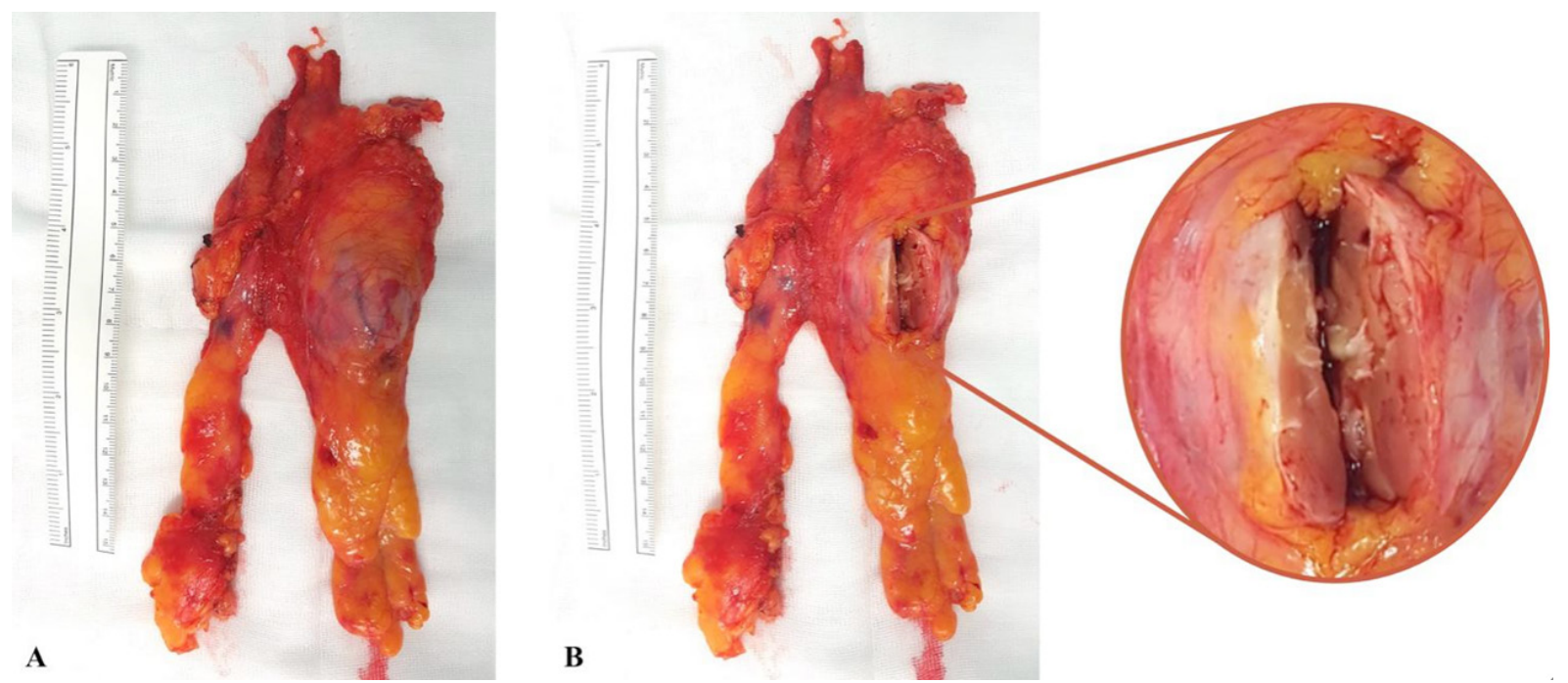

Figure 5. A: Gross specimen after en bloc video-assisted thoracic surgery thymectomy; B: gross cross section revealing a thymoma 3.5 $\mathrm{cm} \times 3 \mathrm{~cm}$ in size (the zoomed-in nodule is shown in the circle)

Aramini et al ${ }^{[49]}$ described the subxiphoid thymectomy approach aided by a double sternum retractor to better visualize the mass at the level of the anterior mediastinum, particularly in patients with large invasive tumors. The double sternum retractors provide the surgeon with a better view of the tumor, improving the surgical technique and thus preserving the principles of surgical radicality related to the surgical margins.

\section{VATS AND ROBOTIC-ASSISTED THORACOSCOPIC SURGERY THYMECTOMY}

VATS was introduced in the 1990s; since then, it has totally changed thoracic surgeons' approach to surgery. The advantages of minimally invasive techniques (MIT) compared with conventional open approaches are well known: shorter hospital stay, quicker recovery, better aesthetic result, lower perioperative morbidity, minor surgical access trauma, postoperative pain, and better preservation of pulmonary function. Despite this, the use of MITs in thymic surgery is still controversial. The main surgeons' concerns relate to the higher risk of rupture of the capsule with the consequent spread of tumoral cells, increased risk of local recurrence, and reduced safety margins [Figure 5].

Although recent studies have reported similar oncological outcomes for early-stage thymoma resections performed both by open and minimally invasive approaches ${ }^{[50-53]}$, the first one remains the gold standard treatment ${ }^{[19]}$. This is because evidence is sparse and mostly deriving from case reports or retrospective studies due to the low incidence of these tumors. Moreover, given the indolent behavior of many thymic tumors, an adequate 5-10 years of follow-up should be carried out to establish the exact FFR and overall survival. Currently, few data about long-term follow-ups have been published and therefore statistics are still ineffectual.

No tremor filter, two-dimensional view of the operative field, and inability of the instruments to articulate are well-known VATS limitations, and they make it difficult to operate in such a rigid and tiny space as the mediastinum. The development of robotic technologies has solved some of the above-mentioned problems, allowing a better and safer surgical technique. The robotic system, in fact, is endowed by a three-dimensional, high resolution vision camera that enables the best possible view of the operative site; moreover, every endoscopic procedure around anatomic structures is easier and safer because the surgical EndoWrist can articulate and rotate 360 degrees with seven degrees of freedom articulation. These features make robotic surgery extremely appropriate for thymic surgery, enabling the surgeons to do a safe and 


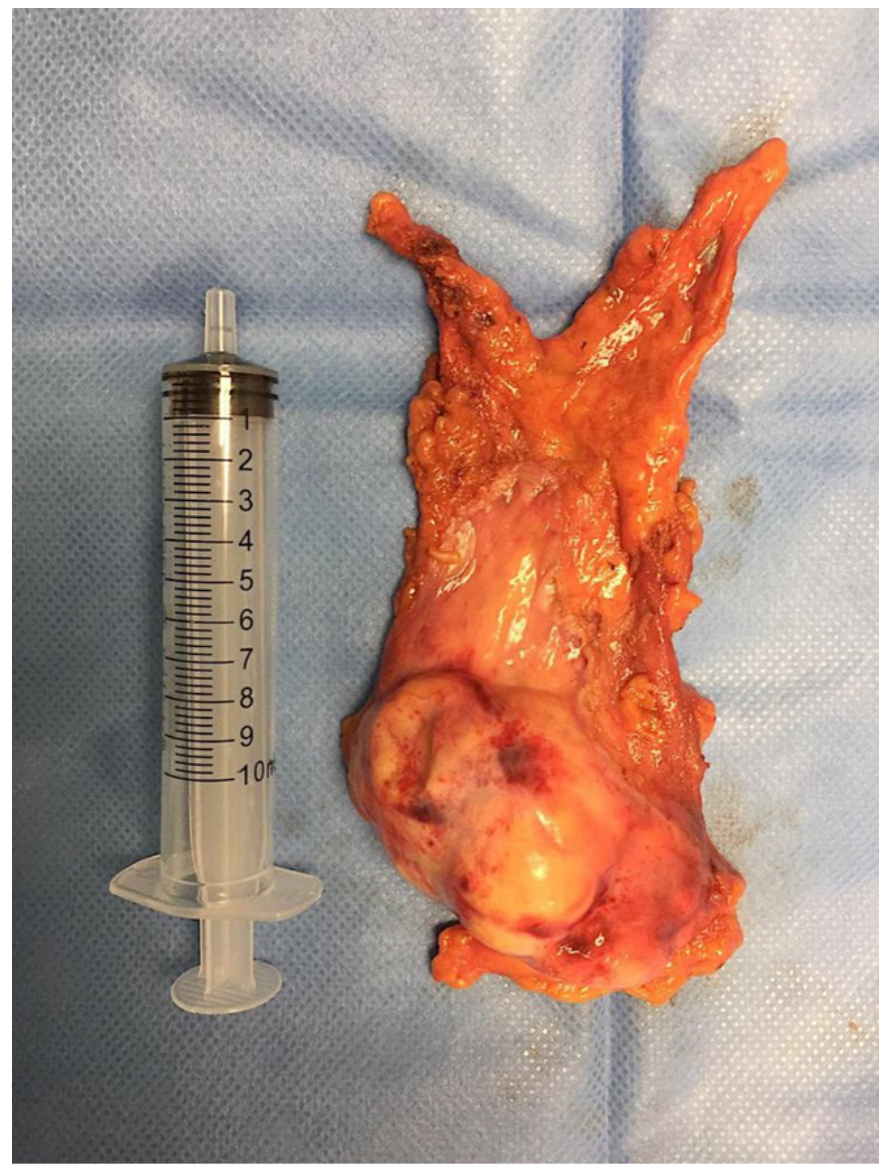

Figure 6. Gross specimen after en bloc video-assisted thoracic surgery thymectomy

comfortable dissection of vascular and nervous structures and a better dissection in remote, fixed, and difficult to reach areas of the neck and mediastinum ${ }^{[11,53-57]}$ [Figure 6].

The main limitations of robotic surgery are the high initial costs, the lack of tactile feedback, and the need of a large enough volume of patients to overcome the initial learning curve.

O'Sullivan et al. ${ }^{[58]}$ recently published a meta-analysis on robotic versus open and video-assisted thoracoscopic surgery approaches for thymectomy, including 18 articles. When comparing robotic $v s$. open thymectomy, evidence shows no differences in operative time, intraoperative complications, and mortality. On the other hand, significantly lower blood loss, fewer postoperative complications, shorter length of hospital stay, and decreased positive margin rate were reported in the robotic group. When comparing robotic vs. VATS thymectomy, instead, the results show no differences in the two groups in terms of operative time, blood loss, length of hospital stay, intraoperative complications, and margin rates. To date, few authors have performed a real comparison between the two techniques, considering not only the perioperative results but also long-term follow-ups [Table 2].

Perioperative parameters were analyzed by Qian et al. ${ }^{[68]}$; when comparing 123 patients with early-stages thymoma who underwent robotic-assisted thoracoscopic surgery (RATS), VATS, or open thymectomy, they found significant differences in blood loss volume, mean postoperative pleural drainage duration, and duration of hospital stay. When comparing two groups for parameters, they found that the outcomes of RATS were more favorable than those of VATS and median sternotomy, while outcomes for VATS 
Table 2. Best evidence papers about minimally invasive thymectomy

\begin{tabular}{|c|c|c|c|c|c|c|}
\hline Ref. & $\begin{array}{c}\text { No. of } \\
\text { patients }\end{array}$ & Surgical approach & $\begin{array}{l}\text { Thymectomy/ } \\
\text { thymomectomy }\end{array}$ & $\begin{array}{l}\text { 5-year survival } \\
\text { rate }(\%)\end{array}$ & RR (\%) & $\begin{array}{l}\text { Mean follow up } \\
\text { (months) }\end{array}$ \\
\hline Roviaro et al. ${ }^{[59]}$ & 22 & uVATS & Thymectomy & 95 & 1.3 & 51.7 \\
\hline Cheng et al. ${ }^{[21]}$ & 44 & UVATS & Thymectomy & 100 & 0 & 36.4 \\
\hline Agasthian and $\operatorname{Lin}^{[60]}$ & 119 & uVATS & Thymectomy & 100 & 3.4 & 58.8 \\
\hline Pennathur et al. ${ }^{[61]}$ & 18 & bVATS & Thymectomy & 100 & 0 & 27 \\
\hline Takeo et al. ${ }^{[51]}$ & 35 & bVATS & Thymectomy & 100 & 2.8 & 65 \\
\hline Mussi et al. ${ }^{[62]}$ & 14 & Robotic & Thymectomy & 100 & 0 & 14.5 \\
\hline Marulli et al. ${ }^{[22]}$ & 79 & Robotic & Thymectomy & 97 & 1.3 & 51.7 \\
\hline Kimura et al. ${ }^{[23]}$ & 45 & UVATS & Thymectomy & 100 & 6.7 & - \\
\hline Marulli et al. ${ }^{[54]}$ & 100 & Robotic & Thymectomy & 100 & 0 & 67 \\
\hline Tseng et al. ${ }^{[83]}$ & 95 & VATS (22) & $\begin{array}{l}\text { Thymectomy (42) } \\
\text { Thymomectomy (53) }\end{array}$ & 100 & $\begin{array}{l}4.5 \\
1,5\end{array}$ & 57 \\
\hline Schneiter et al. ${ }^{[63]}$ & 20 & Robotic & Thymectomy & 100 & 11.1 & 26 \\
\hline Liu et al. ${ }^{[64]}$ & 76 & UVATS & Thymectomy & 100 & 2.6 & 61.9 \\
\hline Ye et al. ${ }^{[65]}$ & 125 & UVATS & Thymectomy & 100 & 0 & 16.9 \\
\hline Keijzers et al. ${ }^{[66]}$ & 37 & Robotic & Thymectomy & 100 & 2.7 & 36 \\
\hline Bae et al. ${ }^{[82]}$ & 342 & $\begin{array}{l}\text { VATS (119) } \\
\text { Transervical (1) } \\
\text { RATS (1) }\end{array}$ & $\begin{array}{l}\text { Thymectomy (239) } \\
\text { Thymomectomy (103) }\end{array}$ & $\begin{array}{l}99 \\
100\end{array}$ & $\begin{array}{l}12.1 \\
9.7\end{array}$ & $\begin{array}{l}94.5 \\
85.6\end{array}$ \\
\hline Guet al. ${ }^{[80]}$ & 1,047 & VATS (277) & $\begin{array}{l}\text { Thymectomy (220) } \\
\text { Thymomectomy (57) }\end{array}$ & $\begin{array}{l}93 \\
96\end{array}$ & $\begin{array}{l}3.1 \\
5.4\end{array}$ & 38 \\
\hline Nakagawa et al. ${ }^{[81]}$ & 1,286 & VATS (169) & $\begin{array}{l}\text { Thymectomy (276) } \\
\text { Thymomectomy (276) }\end{array}$ & $\begin{array}{l}97.3 \\
96.9\end{array}$ & $\begin{array}{l}4 \\
1.8\end{array}$ & 53 \\
\hline Narm et al. ${ }^{[79]}$ & 762 & VATS (297) & $\begin{array}{l}\text { Thymectomy (76) } \\
\text { Thymomectomy (72) }\end{array}$ & $\begin{array}{l}97 \\
96.3\end{array}$ & $\begin{array}{l}4.1 \\
3.7\end{array}$ & 49 \\
\hline Marulli et al. ${ }^{[1]]}$ & 134 & Robotic & Thymectomy & 100 & 0.7 & 48 \\
\hline Rusidanmu et al. ${ }^{[77]}$ & 118 & $\begin{array}{l}\text { VATS } \\
\text { (unspecified) }\end{array}$ & $\begin{array}{l}\text { Thymectomy (43) } \\
\text { Thymomectomy ( } 75)\end{array}$ & $\begin{array}{l}88.4^{\star} \\
98.7^{\star}\end{array}$ & $\begin{array}{l}6.98 \\
2.67\end{array}$ & - \\
\hline Weng et $\left.a\right|^{[67]}$ & 358 & VATS & Thymectomy & 94.5 & 8 & 60.5 \\
\hline
\end{tabular}

*10-year survival rate. RR: recurrence rate; RATS: robotic-assisted thoracoscopic surgery; VATS: video-assisted thoracic surgery; uVATS: uniportal VATS; bVATS: biportal VATS

were more favorable than those of sternotomy. Similar findings were reported by Şehitogullari et al. ${ }^{[69]}$. In a recent analysis, they compared 21 vs. 24 patients who underwent RATS or VATS thymectomy. They found significant differences in terms of mean operative time, length of hospital-stay, and duration of pleural drainage, while mean operative time, operative pain, and remission rates were superimposable. Rückert et al. ${ }^{[70]}$ performed a retrospective analysis on 74 vs. 79 patients with MG who underwent robotic or thoracoscopic thymectomy. With a follow-up of 42 months, they found a significant difference in cumulative complete remission rate of MG between the two groups in favor of the robotic one $(39.25 \% \mathrm{vs}$. $20.3 \%, P=0.01$ ); no differences were found in terms of conversion rate, operative time, and postoperative complications.

Burt et al. ${ }^{[71]}$ recently performed a retrospective multicenter analysis on 943 patients who underwent MIT or open thymectomy by focusing on Ro status as the primary outcome. By comparison, they found a nonsignificant difference in the Ro resection rate for patients treated with minimally invasive or open approach ( $83.4 \%$ vs. $79.4 \%)$, stating that the probability of achieving Ro resection for early-stage thymoma is not influenced by a minimally invasive approach, and MIT is equivalent to OT in this regard. Kamel et al. ${ }^{[72]}$ published a recent multi-institutional analysis on 2,558 performed thymectomies using an open, VATS, or RATS approach. They found that patients who underwent thymectomy via an open approach were younger, had more advanced tumors, had more incomplete resections ( $32 \% v s .30 \%$, and $23 \% ; P=0.013$ ), less frequently underwent regional lymph node dissection, and had longer hospital stays compared to the VATS and robotic groups. When they performed a matched analysis, all those differences became not statistically significant and the three approaches resulted superimposable. 


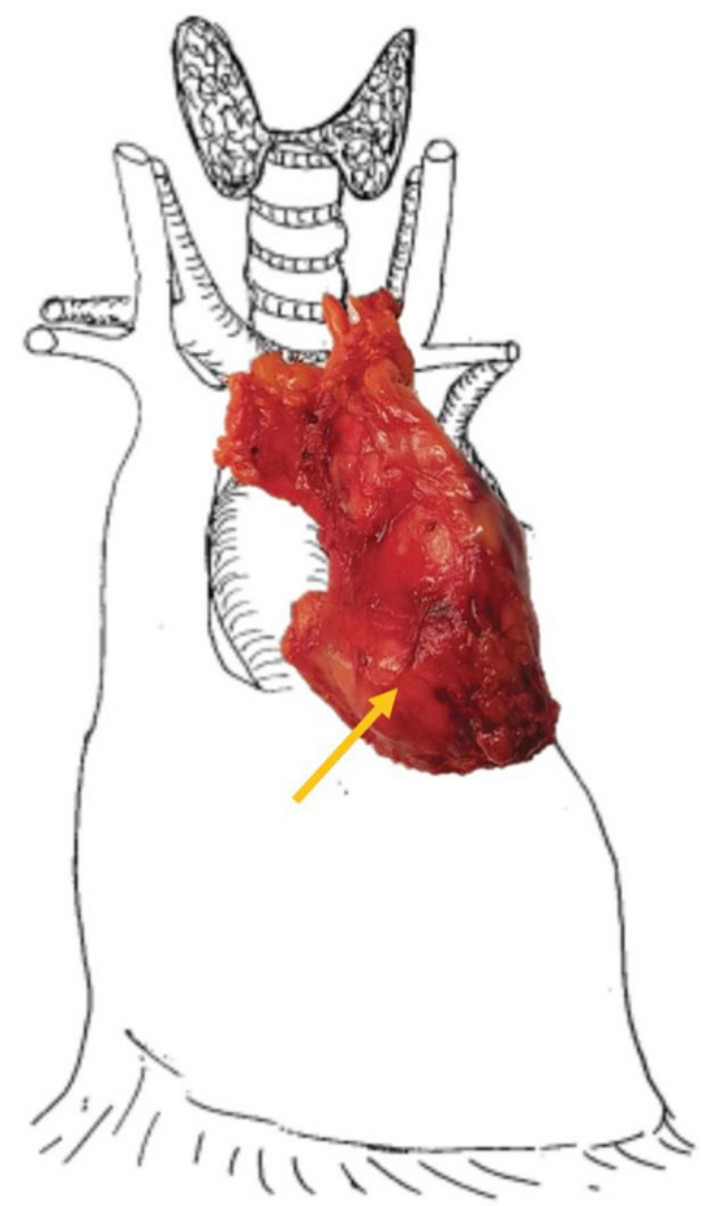

Figure 7. Gross specimen after robotic-assisted thoracoscopic surgery thymomectomy performed for a small intracapsular thymoma (yellow arrow)

Therefore, all published studies do not solve the doubts about which approach should be better among all the available ones and, thus far, no prospective randomized trials have been performed to clear them. For this reason, the choice should be done by the surgeons on the basis of both available evidence and surgeons' personal skills and preferences.

\section{RADICALITY: THYMOMECTOMY OR THYMECTOMY?}

All guidelines and large retrospective review studies recommend the complete en bloc thymectomy as the current gold standard in all resectable thymic lesions because of the risk of a multicentric thymoma development, the occurrence of MG after the operation, and the prevention of the local recurrences ${ }^{[10,73-76]}$. However, many authors have proposed the resection of the thymoma without the rest of the thymic gland as a feasible and safe resection in early stage thymomas (Stages I and II) without $\mathrm{MG}^{[77-86]}$ [Figure 7].

Fiorelli et al ${ }^{[87]}$ recently published the best evidence about equivalence in terms of oncological outcomes of thymomectomy and thymectomy in patients with early stage thymoma. They found ten papers, and most of which showed no statistical differences in terms of local recurrence, while differences were described in terms of surgical outcomes (operative time, blood loss, drainage duration, and hospital stay) in favor of the thymomectomy.

Among these studies, the largest multicentric ones ${ }^{[8,81]}$ were those with a proved higher rate of local recurrence in the thymomectomy group than in the thymectomy one. Gu et al. ${ }^{[80]}$, in their multicenter 
study from the Chinese Alliance for Research in Thymoma database, retrospectively analyzed 1,047 patients who underwent thymomectomy or thymectomy for early stages thymoma; they found a higher recurrence rate in the thymomectomy group, especially for patients with Stage II thymomas ( $14.5 \% v s .2 .9 \%, P=0.001)$. Similarly, Nakagawa et al. ${ }^{[81]}$, in their multicenter study from the JART database, retrospectively analyzed 1286 patients who underwent thymomectomy or thymectomy for early stages thymoma before and after propensity score analysis; they found a higher recurrence rate in the thymomectomy group $(2.1 \% v \mathcal{~ s . ~} 0.41 \%$, $P=0.06)$.

Masaoka ${ }^{[88]}$ published an anecdotal study about his surgical experience in Osaka and Nagoya. In the first experience, most of the 93 patients underwent simple thymomectomies, whereas a majority of patients in the Nagoya series underwent extended thymectomies; in the early 1980s, simple thymomectomy was the procedure of choice, later replaced by extended thymectomy. He found that overall survival rates of the Nagoya series were superior to those of the Osaka one $(87.1 \%$ vs. $66.7 \%$ for Stage I; $80.6 \%$ vs. $60.0 \%$ for Stage II).

Voulaz et al. ${ }^{[89]}$ published the first study about 157 patients who underwent thymectomy or thymomectomy, comparing for the first time long-term outcomes for advanced-stage thymomas and carcinomas, while previous reports have focused only on early stages. They found that oncologic outcomes in terms of disease-free survival rate of thymomectomy $v s$. thymectomy were superimposable and their median followup was 77 months.

To date, there is no prospective study comparing the two approaches and the evidence is still sparse, deriving from retrospective, single-institution, and small studies. The largest published analyses prove that thymomectomy alone is not enough from an oncological point of view for early-stage thymoma. Moreover, given the indolent behavior of these tumors, long-term follow-ups are needed to assess the real rates of recurrence and the superiority of one technique to another.

\section{LYMPHADENECTOMY}

For many years, the role of lymphadenectomy of the mediastinum for thymic lesions has not been made clear, and this surgical procedure has long been underperformed. Despite this, lymph node metastases have proven to be a significant, independent, and adverse factor for FFR in patients with thymic carcinoma and thymoma. To date, no clear guidelines are available regarding lymph node dissection and data from the majority of studies show that lymph node sampling is not routinely performed during surgeries, except in Japan where lymphadenectomy has traditionally been a part of the thymic resection.

The Masaoka staging system included $\mathrm{N}$ involvement in Stage IVb but made no distinction among the different nodal stations ${ }^{[88]}$. The eighth edition of tumor, node, and metastasis classification for thymic tumors, instead, has classified nodal stations into anterior (N1) and deep (N2) regional nodes; their involvement stage lesions as IVa or IVb disease ${ }^{[90]}$.

Anterior mediastinal lymph nodes seem to be the primary drainage basin for thymic epithelial tumors and lymphatic diffusion apparently spreads from the anterior to the deep nodes following a right route. This has been determined based on frequency and pattern of metastasis in addition to anatomical location: nodal metastases are located in the anterior mediastinum in $90 \%$ of thymomas and carcinoids and $70 \%$ of thymic carcinomas $^{[91]}$.

The actual incidence of lymph node metastasis has not been well established. Historically, the prevalence of lymph nodes involvement has been described ranging from $1.8 \%$ to $5.1 \%$ in thymomas and from $20 \%$ to 
$33.5 \%$ in thymic carcinomas and NETs, but these rates could be underestimated because lymphadenectomy is rarely performed by most institutions ${ }^{[91-95]}$.

Two factors have been described to explain lymph node metastasis, namely WHO subtype and tumor size, being both closely related to the biologic aggressiveness of the tumor ${ }^{[96,97]}$. Hwang et al ${ }^{[92]}$ described lymph node metastasis rate according to WHO histologic types as 5\% for Type A, 1.6\% for Type AB, 4.8\% for Type B1, 9.5\% for Type B2, 10.7\% for Type B3, and 31.8\% for thymic carcinoma. They also found that lymph node metastasis rate was higher in tumor larger than $6 \mathrm{~cm}$. Moreover, most authors have reported lymph node metastasis to be more frequent in tumors invading adjacent organs; these findings suggest lymph node dissection to be performed at least in those patients undergoing en bloc resection of thymus and neighboring organs for carcinomas and carcinoids ${ }^{[97,98]}$.

Park et al. ${ }^{[98]}$ suggested dissection of more than 10 lymph nodes to be enough for adequate staging. They retrospectively reviewed 45 patients who underwent thymic resection for carcinoma; during the surgery, they performed lymphadenectomy of a mean of 9.4 lymph nodes and divided the patients in four groups according to the extension of lymph node dissection: no lymph node dissection $(\mathrm{Nx})$, node-negative by $<10$ nodes dissection (Noa), node-negative by $>10$ nodes dissection (Nob), and node metastasis (N1). They found that the five-year FFR rates were $33.3 \%$ in N1, 64.1\% in Noa, $75 \%$ in Nx, and $90 \%$ in Nob, while the five-year DFS rates were $33.3 \%$ in N1, $48.1 \%$ in Noa, $75 \%$ in Nx, and $90 \%$ in Nob.

Although no evidence has proved it yet, it is possible that surgeons with expertise in minimally invasive lobectomy and lymphadenectomy for lung cancer may easily endorse the idea of nodal dissection, to be performed at least in advanced thymomas involving neighboring structures, large masses, and thymic carcinomas.

\section{CONCLUSION}

Radical en bloc thymectomy including the upper cervical poles and the surrounding mediastinal fat is the gold standard treatment for non-MG thymoma and adequate margins are considered the most important prognostic factors.

Open approaches remain the gold standard treatment, but minimally invasive techniques could be effectively used in small, early-stages thymic masses, above all because, despite the shortage of studies, the rate of radicality would seem to be slightly higher for minimally invasive techniques. Transcervical, subxiphoid, thoracoscopic, and/or robotic approaches have been described and compared in many studies, each having advantages and drawbacks. However, the lack of prospective randomized trials still gives no answer about which approach should be better among the available ones. Moreover, the concept of radicality should include pathological features of surgical removal (resection must involve the thymoma, thymus, and mediastinal fat) and operation modalities: minimally invasive resection of a thymic neoplasm does not require the use of rib retractor or the execution of sternotomy. The goal is to perform a complete resection using a video monitor, and the service incision to remove the neoplasm must be large enough not to damage the operating piece during extraction. Therefore, minimally invasive surgery is to be preferred to open techniques not only in terms of radicality but also for the best postoperative performance (less pain and aesthetic result).

Although several authors have proposed thymomectomy as a valid limited resection technique, appropriate for patients with small and early-stages thymomas, still little evidence supports its oncological and longterm advantages.

Finally, the role of lymphadenectomy of the mediastinum for thymic lesions has not been clarified, and this surgical procedure has long been underperformed. Since WHO subtype, tumor size, and invasion of 
neighboring organs have been proved to often be associated with lymph node metastasis, evidence suggests that nodal dissection should be performed at least in advanced thymomas, large masses, and thymic carcinomas.

\section{DECLARATIONS}

\section{Authors' contributions}

Made substantial contributions to conception and design of the study and performed data analysis and interpretation: De Iaco G, Brascia D, Marulli G

Performed data acquisition, as well as provided administrative, technical, and material support: Geronimo A, Sampietro D, Fiorella A, Schiavone M, Panza T, Signore F

Drafting of the manuscript: De Iaco G, Brascia D, Marulli G

Critical revision: Marulli G

\section{Availability of data and materials}

Not applicable.

\section{Financial support and sponsorship}

None.

\section{Conflicts of interest}

All authors declared that there are no conflicts of interest.

\section{Ethical approval and consent to participate}

Not applicable.

\section{Consent for publication}

Not applicable.

\section{Copyright}

(c) The Author(s) 2020.

\section{REFERENCES}

1. Conkle DM, Adkins RB. Primary malignant tumors of the mediastinum. Ann Thorac Surg 1972;5:533-67.

2. Burkell CC, Cross JM, Kent HP, Nanson EM. Mass lesions of the mediastinum. Curr Probl Surg 1969:2-57.

3. Wick MR, Scheithauer BW, Weiland LH, Bernatz PE. Primary thymic carcinomas. Am J Surg Pathol 1982;7:613-30.

4. Davis RD, Oldham HN, Sabiston DC. Primary cysts and neoplasms of the mediastinum: recent changes in clinical presentation, methods of diagnosis, management, and results. Ann Thorac Surg 1987;3:229-37.

5. Detterbeck FC, Zeeshan A. Thymoma: current diagnosis and treatment. Chin Med J 2013;126:2186-91.

6. Regnard JF, Magdeleinat P, Dromer C, Dulmet E, de Montpreville V, et al. Prognostic factors and long-term results after thymoma resection: a series of 307 patients. J Thorac Cardiovasc Surg 1996;112:376-84.

7. Kondo K, Monden Y. Therapy for thymic epithelial tumors: a clinical study of 1,320 patients from Japan. Ann Thorac Surg 2003;76:878-84.

8. Kelly RJ, Petrini I, Rajan A, Wang Y, Giaccone G, et al. Thymic malignancies: from clinical management to targeted therapies. J Clin Oncol 2011;29:4820-7.

9. Kamel MK, Stiles BM, Ghaly G, Rahouma M, Nasar A, et al. Predictors of pleural implants in patients with thymic tumors. Ann Thorac Surg 2016;102:1647-52.

10. Toker A, Sonett J, Zielinski M, Rea F, Tomulescu V, et al. Standard terms, definitions, and policies for minimally invasive resection of thymoma. J Thorac Oncol 2011;6:S1739-42.

11. Marulli G, Maessen J, Melfi F, Schmid TA, Keijzers M, et al. Multi-institutional European experience of robotic thymectomy for thymoma. Ann Cardiothorac Surg 2016;5:18-25.

12. Detterbeck FC, Moran C, Huang J, Suster S, Walsh G, et al. Which way is up? Policies and procedures for surgeons and pathologists regarding resection specimens of thymic malignancy. J Thorac Oncol 2011;6:S1730-8.

13. Huang J, Detterbeck FC, Wang Z, Loehrer PJ Sr. Standard outcome measures for thymic malignancies. J Thorac Oncol 2010;5:2017-23. 
14. Detterbeck FC. Evaluation and treatment of stage I and II thymoma. J Thorac Oncol 2010;5:S318-22.

15. Novellino L, Longoni M, Spinelli L, Andretta M, Cozzi M, et al. "Extended" thymectomy without sternotomy, performed by cervicotomy and thoracoscopic techniques in the treatment of myasthenia gravis. Int Surg 1994;79:378-81.

16. Zieliński M, Kuzdzał J, Szlubowski A, Soja J. Transcervical-subxiphoid-videothoracoscopic "maximal” thymectomy--operative technique and early results. Ann Thorac Surg 2004;78:404-9.

17. Jaretzki A. Thymectomy for myasthenia gravis analysis of the controversies regarding technique and results. Neurology 1997;48:52-63.

18. Gellert K, Bottger J, Martin T, Werner J, Mangler C, et al. Thoracoscopic thymectomy in the treatment concept for myasthenia gravis. Surg Technol Int 2005;14:99-104.

19. Masaoka A, Monden Y, Nakahara K, Tanioka T. Follow-up study of thymomas with special reference to their clinical stages. Cancer 1981;48:2485-92.

20. Ruffini E, Filosso PL, Guerrera F, Lausi P, Lyberis P, et al. Optimal surgical approach to thymic malignancies: new trends challenging old dogmas. Lung Cancer 2018;118:161-70.

21. Cheng YJ, Hsu JS, Kao EL. Characteristics of thymoma successfully resected by videothoracoscopic surgery. Surg Today 2007;37:192-6.

22. Marulli G, Rea F, Melfi F, Schmid TA, Ismail M, et al. Robot aided thoracoscopic thymectomy for early-stage thymoma: a multicenter European study. J Thorac Cardiovasc Surg 2012;144:1125-30.

23. Kimura T, Inoue M, Kadota Y, Shiono H, Shintani Y, et al. The oncological feasibility and limitations of video-assisted thoracoscopic thymectomy for early-stage thymomas. Eur J Cardiothorac Surg 2013;44:e214-8.

24. Agatsuma H, Yoshida K, Yoshino I, Okumura M, Higashiyama M, et al. Video-assisted thoracic surgery thymectomy versus sternotomy thymectomy in patients with thymoma. Ann Thorac Surg 2017;104:1047-53.

25. Toker A. Standardized definitions and policies of minimally invasive thymoma resection. Ann Cardiothorac Surg 2015;4:535-9.

26. Schumacher E, Roth J. Thymektomie bei cenum Fall von Morbus Basedowii mitmyasthenia. Mit a d Grezgeb d Med Chir 1912;25:746.

27. Crile G Jr. Thymectomy through the neck. Surgery 1966;59:213-5.

28. Kirschner PA, Osserman KE, Kark AE. Studies in myasthenia gravis: transcervical total thymectomy. JAMA 1969;209:906-10.

29. Kark AE, Kirschner PA. Total thymectomy by the transcervical approach. Br J Surg 1971;58:321-6.

30. Cooper JD, Al-Jilaihawa AN, Pearson FG, Humphrey JG, Humphrey HE. An improved technique to facilitate transcervical thymectomy for myasthenia gravis. Ann Thorac Surg 1988;45:242-7.

31. Coosemans W, Lerut TE, Van Raemdonck DE. Thoracoscopic surgery: the Belgian experience. Ann Thorac Surg 1993;56:721-30.

32. Calhoun RF, Ritter JH, Guthrie TJ, Pestronk A, Meyers BF, et al. Results of transcervical thymectomy for myasthenia gravis in 100 consecutive patients. Ann Surg 1999;230:555-61.

33. Lemaître PH, Keshavjee S. Uniportal video-assisted transcervical thymectomy. Thorac Surg Clin 2019;29:187-94.

34. Ampollini L, Del Rio P, Sianesi M, Rusca M, Carbognani P. Transcervical video-assisted thymectomy: preliminary results of a modified surgical approach. Langenbecks Arch Surg 2011;396:267-71.

35. Yu L, Shan M, Jiang J, Jing Y, Zang N, et al. Combined transcervical and unilateral-thoracoscopic thymectomy for myasthenia gravis: 2 years of follow-up. Surg Laparosc Endosc Percutan Tech 2008;18:489-92.

36. Kido T, Hazama K, Inoue Y, Tanaka Y, Takao T. Resection of anterior mediastinal masses through an infrasternal approach. Ann Thorac Surg 1999;67:263-5.

37. Hsu CP, Chuang CY, Hsu NY, Shia SE. Subxiphoid approach for video-assisted thoracoscopic extended thymectomy in treating myasthenia gravis. Interact Cardiovasc Thorac Surg 2002;1:4-8.

38. Suda T, Sugimura H, Tochii D, Kihara M, Hattori Y. Single-port thymectomy through an infrasternal approach. Ann Thorac Surg 2012;93:334-6.

39. Suda T. Uniportal subxiphoid video-assisted thoracoscopic thymectomy. J Vis Surg 2016;2:123.

40. Suda T, Ashikari S, Tochii D, Tochii S, Takagi Y. Dual-port thymectomy using subxiphoid approach. Gen Thorac Cardiovasc Surg 2014;62:570-2.

41. Suda T, Tochii D, Tochii S, Takagi Y. Trans-subxiphoid robotic thymectomy. Interact CardioVasc Thorac Surg 2015;20:669-71.

42. Suda T. Robotic subxiphoid thymectomy. J Vis Surg 2016;2:118.

43. Zhang L, Li M, Jiang F, Zhang Z, Zhang Q, et al. Subxiphoid versus lateral intercostal approaches thoracoscopic thymectomy for nonmyasthenic early-stage thymoma: a propensity score -matched analysis. Int J Surg 2019;67:13-7.

44. Suda T. Subxiphoid thymectomy: single-port, dual-port, and robot-assisted. J Vis Surg 2017;3:75.

45. Wu L, Lin L, Liu M, Jiang L, Jiang G. Subxiphoid uniportal thoracoscopic extended thymectomy. J Thorac Dis 2015;7:1658-60.

46. Weaver H, Ali JM, Jiang L, Yang C, Wu L, et al. Uniportal subxiphoid video-assisted thoracoscopic approach for thymectomy: a case series. J Vis Surg 2017;3:169.

47. Numanami H, Yano M, Yamaji M, Taguchi R, Furuta C, et al. Thoracoscopic thymectomy using a Subxiphoid approach for anterior mediastinal tumors. Ann Thorac Cardiovasc Surg 2018;24:65-72.

48. Zieliński M, Czajkowski W, Gwozdz P, Nabialek T, Szlubowski A, et al. Resection of thymomas with use of the new minimally-invasive technique of extended thymectomy performed through the subxiphoid-right video-thoracoscopic approach with double elevation of the sternum. Eur J Cardiothorac Surg 2013;44:e113-9.

49. Aramini B, Song N, Banchelli F, Jiang G, Gonzalez-Rivas D, et al. Subxiphoid thymectomy with a double sternum retractor: a pilot study. Gland Surg 2019;8:657-62.

50. Odaka M, Akiba T, Mori S, Asano H, Marushima H, et al. Oncological outcomes of thoracoscopic thymectomy for the treatment of stages I-III thymomas. Interact Cardiovasc Thorac Surg 2013;17:285-90. 
51. Takeo S, Tsukamoto S, Kawano D, Katsura M. Outcome of an original video-assisted thoracoscopic extended thymectomy for thymoma. Ann Thorac Surg 2011;92:2000-5.

52. Cheng YJ, Kao EL, Chou SH. Videothoracoscopic resection of stage II thymoma: prospective comparison of the results between thoracoscopy and open methods. Chest 2005;128:3010-2.

53. Rea F, Schiavon M, Di Chiara F, Marulli G. Single-institution experience on robot-assisted thoracoscopic operations for mediastinal disease. Innovations 2011;6:316-22.

54. Marulli G, Schiavon M, Persinotto E, Bugana A, Di Chiara F, et al. Surgical and neurologic outcomes after robotic thymectomy in 100 consecutive patients with myasthenia gravis. J Thorac Cardiovasc Surg 2013;145:730-6.

55. Rea F, Marulli G, Bortolotti L, Feltracco P, Zuin A, et al. Experience with the "Da Vinci" robotic system for thymectomy in patients with myasthenia gravis: report of 33 cases. Ann Thorac Surg 2006;81:455-9.

56. Marulli G, Comacchio GM, Rea F. Robotic thymectomy: technical tips. Video-assist Thorac Surg 2017;2:6.

57. Marulli G, Rea F, Melfi F, Schmid TA, Ismail M, et al. Robot-aided thoracoscopic thymectomy for early-stage thymoma: a multicentre European study. Ann Thorac Surg 2006;81:455-9.

58. O'Sullivan KE, Kreaden US, Hebert AE, Eaton D, Redmond KC. A systematic review of robotic versus open and video assisted thoracoscopic surgery (VATS) approaches for thymectomy. Ann Cardiothorac Surg 2019;8:174-93.

59. Roviaro G, Varoli F, Nucca O, Vergani C, Maciocco M. Videothoracoscopicapproach to primary mediastinal pathology. Chest 2000;117:1179-83.

60. Agasthian T, Lin S. Clinical outcome of videoassisted thymectomy for myasthenia gravis and thymoma. Asian Cardiovasc Thorac Ann 2010;18:234-9.

61. Pennathur A, Qureshi I, Schuchert MJ, Dhupar R, Ferson PF, et al. Comparison of surgical techniques for early-stage thymoma: feasibility of minimally invasive thymectomy and comparison with open resection. J Thorac Cardiovasc Surg 2011;141:694-701.

62. Mussi A, Fanucchi O, Davini F, Lucchi M, Picchi A, et al. Robotic extended thymectomy for early-stage thymomas. Eur J Cardiothorac Surg 2012;41:e43-6.

63. Schneiter D, Tomaszek S, Kestenholz P, Hillinger S, Opitz I, et al. Minimally invasive resection of thymomas with the da Vinci® Surgical System. Eur J Cardiothorac Surg 2013;43:288-92.

64. Liu TJ, Lin MW, Hsieh MS, Kao MW, Chen KC, et al. Video-assisted thoracoscopic surgical thymectomy to treat early thymoma: a comparison with the conventional transsternal approach. Ann Surg Oncol 2014;21:322-8.

65. Ye B, Tantai JC, Ge XX, Li W, Feng J, et al. Surgical techniques for early-stage thymoma: video-assisted thoracoscopic thymectomy versus transsternal thymectomy. J Thorac Cardiovasc Surg 2014;147:1599-603.

66. Keijzers M, de Baets M, Hochstenbag M, Abdul-Hamid M, Zur Hausen A, et al. Robotic thymectomy in patients with myasthenia gravis: neurological and surgical outcomes. Eur J Cardiothorac Surg 2015;48:40-5.

67. Weng W, Li X, Meng S, Liu X, Peng P, et al. Video-assisted thoracoscopic thymectomy is feasible for large thymomas: a propensitymatched comparison. Interact CardioVasc Thorac Surg 2020;30:565-72.

68. Qian L, Chen X, Huang J, Lin H, Mao F, et al. A comparison of three approaches for the treatment of early-stage thymomas: robotassisted thoracic surgery, video-assisted thoracic surgery, and median sternotomy. J Thorac Dis 2017;9:1997-2005.

69. Şehitogullari A, Nasır A, Anbar R, Erdem K, Bilgin C. Comparison of perioperative outcomes of videothoracoscopy and robotic surgical techniques in thymoma. Asian J Surg 2020;43:244-50.

70. Rückert JC, Swierzy M, Ismail M. Comparison of robotic and nonrobotic thoracoscopic thymectomy: a cohort study. J Thorac Cardiovasc Surg 2011;141:673-7.

71. Burt BM, Nguyen D, Groth SS, Palivela N, Ripley RT, et al. Utilization of minimally invasive thymectomy and margin-negative resection for early-stage thymoma. Ann Thorac Surg 2019;108:405-11.

72. Kamel MK, Villena-Vargas J, Rahouma M, Lee B, Harrison S, et al. National trends and perioperative outcomes of robotic resection of thymic tumours in the United States: a propensity matching comparison with open and video-assisted thoracoscopic approaches. Eur J Cardiothorac Surg 2019;56:762-9.

73. Girard N, Ruffini E, Marx A, Faivre-Finn C, Peters S. ESMO guidelines committee thymic epithelial tumours: ESMO clinical practice guidelines for diagnosis, treatment and follow-up. Ann Oncol 2015;26:v40-55.

74. NCCN. Clinical practice guidelines in oncology. Thymic malignancies 2017. Available from: https://www.nccn.org/store/login/login. aspx?ReturnURL=https://www.nccn.org/professionals/physician_gls/pdf/thymic_blocks.pdf [Last accessed on 22 Aug 2020]

75. Falkson CB, Bezjak A, Darling G, Gregg R, Malthaner R, et al. The management of thymoma: a systematic review and practice guideline. J Thorac Oncol 2009;4:911-9.

76. Girard N, Mornex F, Van Houtte P, Cordier JF, van Schil P. Thymoma: a focus on current therapeutic management. J Thorac Oncol 2009;4:119-26.

77. Rusidanmu A, Huang S, Lv X. Is thymomectomy sufficient for nonmyasthenic early stage thymoma patients? A retrospective, single center experience. Thorac Cancer 2018;9:88-93.

78. Tassi V, Ceccarelli S, Zannori C, Gili A, Daddi N, et al. Could thymomectomy be a reasonable option for non-myasthenic thymoma patients? J Thorac Dis 2017;9:3817-24.

79. Narm KS, Lee CY, Do YW, Jung HS, Byun GE, et al. Limited thymectomy as a potential alternative treatment option for early-stage thymoma: a multi-institutional propensity-matched study. Lung Cancer 2016;101:22-7.

80. Gu Z, Fu J, Shen Y, Wei Y, Tan L, et al. Thymectomy versus tumor resection for early-stage thymic malignancies: a Chinese Alliance for Research in Thymomas retrospective database analysis. J Thorac Dis 2016;8:680-6. 
81. Nakagawa K, Yokoi K, Nakajima J, Tanaka F, Maniwa Y, et al. Is thymomectomy alone appropriate for Stage I (T1N0M0) thymoma? Results of a propensity-score analysis. Ann Thorac Surg 2016;101:520-6.

82. Bae MK, Lee SK, Kim HY, Park SY, Park IK, et al. Recurrence after thymoma resection according to the extent of the resection. J Cardiothorac Surg 2014;9:51.

83. Tseng YC, Hsieh CC, Huang HY, Huang CS, Hsu WH, et al. Is thymectomy necessary in non-myasthenic patients with early thymoma? J Thorac Oncol 2013;8:952-8.

84. Odaka M, Akiba T, Yabe M, Hiramatsu M, Matsudaira H, et al. Unilateral thoracoscopic subtotal thymectomy for the treatment of stage I and II thymoma. Eur J Cardiothorac Surg 2010;37:824-6.

85. Onuki T, Ishikawa S, Iguchi K, Goto Y, Sakai M, et al. Limited thymectomy for stage I or II thymomas. Lung Cancer 2010;68:460-5.

86. Sakamaki Y, Kido T, Yasukawa M. Alternative choices of total and partial thymectomy in video-assisted resection of noninvasive thymomas. Surg Endosc 2008;22:1272-7.

87. Fiorelli A, Natale G, Freda C, Santini M. Is thymomectomy equivalent to complete thymectomy in non-myasthenic patients with earlystage thymoma? Interact CardioVasc Thorac Surg 2019;28:399-403.

88. Masaoka A. Staging system of thymoma. J Thorac Oncol 2010;5:S304-12.

89. Voulaz E, Veronesi G, Infante M, Cariboni U, Testori A, et al. Radical thymectomy versus conservative thymomectomy in the surgical treatment of thymic malignancies. J Thorac Dis 2018;10:4127-36.

90. Bhora FY, Chen DJ, Detterbeck FC, Asamura H, Falkson C, et al. Staging and prognostic factors committee; advisory boards. the ITMIG/ IASLC thymic epithelial tumors staging project: a proposed lymph node map for thymic epithelial tumors in the forthcoming 8th edition of the TNM classification of malignant tumors. J Thorac Oncol 2014;9:88-96.

91. Kondo K, Monden Y. Lymphogenous and hematogenous metastasis of thymic epithelial tumors. Ann Thorac Surg 2003;76:1859-64.

92. Hwang Y, Park IK, Park S, Kim ER, Kang CH, et al. Lymph node dissection in thymic malignancies: implication of the ITMIG lymph node map, TNM stage classification, and recommendations. J Thorac Oncol 2016;1:108-14.

93. Weksler B, Holden A, Sullivan JL. Impact of positive nodal metastases in patients with thymic carcinoma and thymic neuroendocrine tumors. J Thorac Oncol 2015;10:1642-7.

94. Weksler B, Pennathur A, Sullivan JL, Nason KS. Resection of thymoma should include nodal sampling. J Thorac Cardiovasc Surg 2015;149:737-42.

95. Hwang Y, Kang CH, Park S, Lee HJ, Park IK, et al. Impact of lymph node dissection on thymic malignancies: multi-institutional propensity score matched analysis. J Thorac Oncol 2018;13:1949-57.

96. Zhitao G, Yucheng W, Jianhua F, Tan L, Zhang P, et al. Lymph node metastases in thymic malignancies: a Chinese Alliance for Research in Thymomas retrospective databases analysis. Interact CardioVasc Thorac Surg 2017;25:455-61.

97. Hosaka Y, Tsuchida M, Toyabe S, Umezu H, Eimoto T, et al. Masaoka stage and histologic grade predict prognosis in patients with thymic carcinoma. Ann Thorac Surg 2010;89:912-7.

98. Park IK, Kim YT, Jeon JH, Kim HS, Hwang Y, et al. Importance of lymph node dissection in thymic carcinoma. Ann Thorac Surg 2013;96:1025-32. 